\title{
El nexo saber-poder en las reconfiguraciones de un margen en proceso de integración Una mirada desde el Norte La Paz (Bolivia)
}

Rôle de la relation savoirs et pouvoirs dans l'évolution d'une région marginale en voie d'intégration. Analyse depuis le Norte La Paz (Bolivie)

The power/knowledge issue and its function in a periphery undergoing the process of integration: Insight from Northern La Paz (Bolivia)

\section{Laetitia Perrier Bruslé}

\section{OpenEdition}

Journals

Edición electrónica

URL: http://journals.openedition.org/bifea/7662

DOI: $10.4000 /$ bifea.7662

ISSN: 2076-5827

Editor

Institut Français d'Études Andines

Edición impresa

Fecha de publicación: 1 diciembre 2015

Paginación: 387-413

ISSN: 0303-7495

Referencia electrónica

Laetitia Perrier Bruslé, «El nexo saber-poder en las reconfiguraciones de un margen en proceso de integración

Una mirada desde el Norte La Paz (Bolivia) », Bulletin de l'Institut français d'études andines [En línea], 44

(3) | 2015, Publicado el 08 diciembre 2015, consultado el 05 noviembre 2020. URL : http://

journals.openedition.org/bifea/7662 ; DOI : https://doi.org/10.4000/bifea.7662

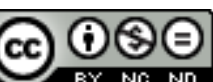

Les contenus du Bulletin de l'Institut français d'études andines sont mis à disposition selon les termes de la licence Creative Commons Attribution - Pas d'Utilisation Commerciale - Pas de Modification 4.0 International. 
Bulletin de l'Institut Français d'Études Andines / 2015, 44 (3): 387-413

\title{
El nexo saber-poder en las reconfiguraciones de un margen en proceso de integración Una mirada desde el Norte La Paz (Bolivia)
}

\author{
Laetitia Perrier Bruslék
}

\begin{abstract}
Resumen
El Norte La Paz corresponde a la parte amazónica del departamento de La Paz. Es un margen histórico del territorio boliviano. Pero a partir de los años 1970 se aceleró la integración de esta región al entorno nacional y global. En este artículo la autora propone analizar las diferentes etapas integracionistas a partir de los actores sociales, evaluando su resiliencia al cambio que depende de su capacidad territorial (o sea de su capacidad de controlar su espacio a diferentes escalas). Dos parámetros fundamentales determinan la capacidad territorial: el acceso a los recursos naturales y el acceso a la información. Es así que el saber (constituido por el conjunto de informaciones) fortalece el poder (la capacidad territorial). Pero se demostrará que si bien es cierto que el poder se constituye gracias a los saberes, este lleva a la producción de nuevos saberes.
\end{abstract}

Palabras clave: integración, capacidad, saber-poder, Bolivia, Norte La Paz

\section{Rôle de la relation savoirs et pouvoirs dans l'évolution d'une région marginale en voie d'intégration. Analyse depuis le Norte La Paz (Bolivie)}

\section{Résumé}

Le Norte La Paz correspond à la partie amazonienne du département de La Paz. À partir des années 1970, l'intégration de cette région au reste du territoire national s'accélère. Dans cet article, l'auteure propose d'analyser ces différentes phases d'intégration à partir des acteurs sociaux, en évaluant leur

* Maitre de conférences en Géographie, Université de Lorraine - Laboratoire PRODIG. Email : laetitia.perrierbrusle@gmail.com 
résilience au changement qui dépend de leur capacité territoriale - c'est-à-dire de leur capacité de contrôler leur espace à différentes échelles. Cette capacité territoriale est déterminée par deux paramètres : I'accès aux ressources et l'accès à l'information. C'est ainsi que le savoir (constitué par l'ensemble des informations reçues par l'acteur) renforce le pouvoir (qui se traduit par une capacité territoriale). Nous irons plus loin en démontrant que si le pouvoir se renforce grâce aux savoirs, il permet aussi de construire de nouveaux savoirs.

Mots-clés : integration, capacité, savoir-pouvoir, Bolivie, Norte La Paz

\title{
The power/knowledge issue and its function in a periphery undergoing the process of integration: Insight from Northern La Paz (Bolivia)
}

\begin{abstract}
Northern La Paz lies in the Amazonian part of La Paz department. Historically, it is situated at the margins of Bolivian territory. Beginning in the $70 \mathrm{~s}$, the integration of this region with the rest of the national territory and global space accelerated. In this article, the author proposes to analyze the different stages of integration by the social actors, assessing their resilience as reflexted in their territorial capacity - that is to say their ability to control their territory. Two parameters determine that capacity: access to resources and access to information. Thus, knowledge (made up of all the information received by the actor) strengthens power (which results in a territorial capacity). M oreover, we will demonstrate that if power is reinforced through knowledge, it also allows to the creation of new knowledge.
\end{abstract}

Keywords: integration, capacity, power/knowledge, Bolivia, Northen La Paz

El Norte La Paz corresponde a la parte amazónica del departamento de La Paz. Es un margen histórico del territorio boliviano. Se caracterizó durante mucho tiempo por un relativo aislamiento físico, una débil presencia estatal contrabalanceada por el poder de control territorial de varios grupos de actores exógenos y/o extraestatales. También se distinguió por la autonomía de la sociedad local, resultante de la incapacidad del Estado central de imponer su orden territorial como se ha observado en otras regiones alejadas (Scott, 2009)- . Por esta razón, siempre presentó rasgos diferentes de una periferia sometida y es preferible utilizar el concepto de margen en lugar de periferia, que se utiliza más para describir las relaciones desiguales entre un centro y sus periferias (Amin, 1973; Raffestin, 1980; Reynaud, 1981).

Esta situación de margen es más el fruto de una construcción histórica que la consecuencia de una posición geográfica alejada del centro. El Norte de La $\mathrm{Paz}$, como las otras regiones orientales, fue relegado físicamente del territorio nacional a pesar de tener un rol simbólico clave en la construcción del territorio ideal (Fifer, 1976; Groff Greever, 1987; Roux, 1997; Roca, 2001; Perrier Bruslé, 2007). Pero esta marginalidad, por ser una construcción social histórica, puede ser reversible. Es lo que sucedió a partir de los años 1970 cuando se aceleró la integración del Norte La Paz al entorno nacional y global. Este proceso se 
desarrolló en varias etapas, cada una caracterizada por un paradigma específico (desarrollista o conservacionista, anclado en una escala nacional o mundial). Cada ciclo integracionista produjo reconfiguraciones sociales y un nuevo mapeo de los actores a escala local. La elección de Evo Morales en 2005 condujo a la última etapa de este proceso de integración. El retorno del Estado intervencionista y un paradigma netamente desarrollista y neoextractivista (Gudynas, 2012) tiene un fuerte impacto en el Norte La Paz. Sin embargo, las huellas que dejaron los ciclos anteriores siguen vigentes; la más fuerte es la toma de poder de los actores locales, herencia de la época neoliberal (1985-2005).

Si bien es cierto que cada etapa integracionista lleva a reconfiguraciones sociales, es importante escapar de la trampa metodológica de analizarlas solamente a partir de los impulsos de los centros exteriores. La sociedad local en el Norte La Paz tiene una dinámica propia. Las reconfiguraciones sociales generadas por cada etapa de integración dependen de la capacidad de resiliencia de los grupos de actores - 0 sea su capacidad de enfrentar y adaptarse a los cambios-. Es cierto que los estudios en torno a la resiliencia de los actores locales no son nuevos. Pero nuestra postura epistemológica que parte de los actores locales y no de los impulsos exteriores tiene algo novedoso. El análisis ya no se concentra en los centros sino en los márgenes. Con este nuevo enfoque metodológico pretendemos aclarar no solamente las capacidades territoriales de los actores sino también la manera cómo estas capacidades permiten escapar a una situación de gran pobreza o marginalidad. Así, este análisis sobre el Norte La Paz participa a una reflexión general sobre la pobreza en Bolivia. Para conducir este análisis partiré de una hipótesis que relaciona las capacidades de los actores con dos parámetros fundamentales: el acceso a los recursos naturales y el acceso a la información. Estos dos parámetros determinan tanto las capacidades territoriales de cada actor como su capacidad de resiliencia al cambio.

Partiendo de esta hipótesis, destacaré dos pautas importantes que contribuyen a una reflexión general sobre la relación entre saberes y poderes en el contexto de un margen boliviano. La primera es que la capacidad territorial, que determina el poder de cada grupo de actores de influir sobre su territorio así como su resiliencia al cambio, depende de las informaciones que el grupo recibe. Es así que la construcción del poder depende de saberes previamente adquiridos. La segunda pauta es que la relación entre saber y poder es todavía más dinámica y compleja. Porque si bien es cierto que el poder se constituye gracias a los saberes, este lleva a la producción de nuevos saberes. Para desarrollar estos dos puntos voy a basarme en el marco conceptual de Armatya Sen en torno a las capacidades y de Michel Foucault sobre la coproducción de los saberes y poderes. Apoyaré mis análisis sobre los resultados de un trabajo de campo en el Norte La Paz que desarrollé entre 2012 y 2015 . Este trabajo permitió colectar más de 40 entrevistas cualitativas con los líderes campesinos, indígenas, representantes del Estado y de las ONG y habitantes del $\mathrm{N}$ orte La Paz. Antes de desarrollar mi análisis presentaré los procesos integracionistas pasados y actuales en el Norte La Paz, a fin de demostrar cuál ha sido el impacto en las capacidades y los poderes de los actores locales. 


\section{UNA REGIÓ N CONTRADICTORIA EN EL CRUCE DE TRAYECTO RIAS DE DESARROLLO}

El N orte La Paz es un margen en proceso de integración. Este proceso se remonta a los primeros tiempos de la Colonia y continúa después de la formación de la República (Calderon, 2014; Mendieta, 2014). Es importante, antes de presentar los procesos contemporáneos de integración y sus impactos en términos de reconfiguración social, subrayar la constancia del deseo de integración que determina la representación

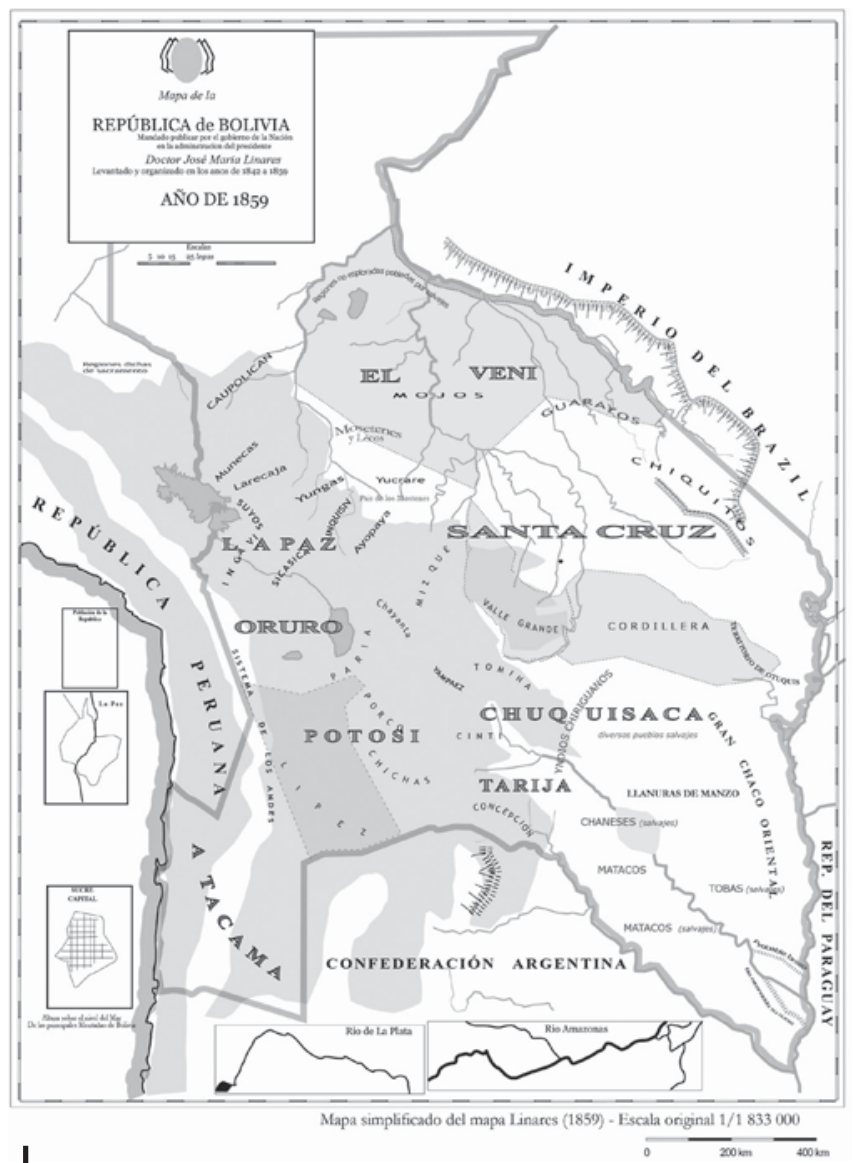

Figura 1 - La representación de la frontera en el mapa Linares de 1859

Esta figura representa una versión simplificada del mapa Linares. Todos los elementos clave del mapa fueron reproducidos en este mapa sintético para facilitar su lectura. Las indicaciones que demuestran el desconocimiento del O riente boliviano en aquella época han sido transcritas en prioridad

(c) Laetitia Perrier Bruslé simbólica de la región y su papel clave en el territorio ideal boliviano.

\section{1. Un margen anclado en el imaginario nacional}

El Norte La Paz es un margen paradójico: está desvinculado y al mismo tiempo está anclado en la representación ideal del territorio boliviano. Desde el inicio de la República, la región se concebía como una frontera en el sentido norteamericano planteado por Jackson Turner al final del siglo XIX (Turner, 1893). Según esta visión, la región se componía de tierras baldías que debían ser conquistadas para que avance la civilización sobre el mundo salvaje (García Jordán, 2001; Perrier Bruslé, 2005). El famoso mapa Linares de 1859, que representa el territorio de Bolivia, muy presente en el imaginario del país (Roux, 1997), muestra los dos resortes de esta representación de frontera: el vacío oriental (toponimia inexistente, falta de información topográfica, escudo nacional colocado en la zona menos conocida para esconder el desconocimiento cartográfico etc.) y la visión de un mundo salvaje (en el Norte figura la mención «regiones no exploradas pobladas por salvajes»). 
Bolivia: el nexo saber-poder en las reconfiguraciones de un margen en proceso de integración

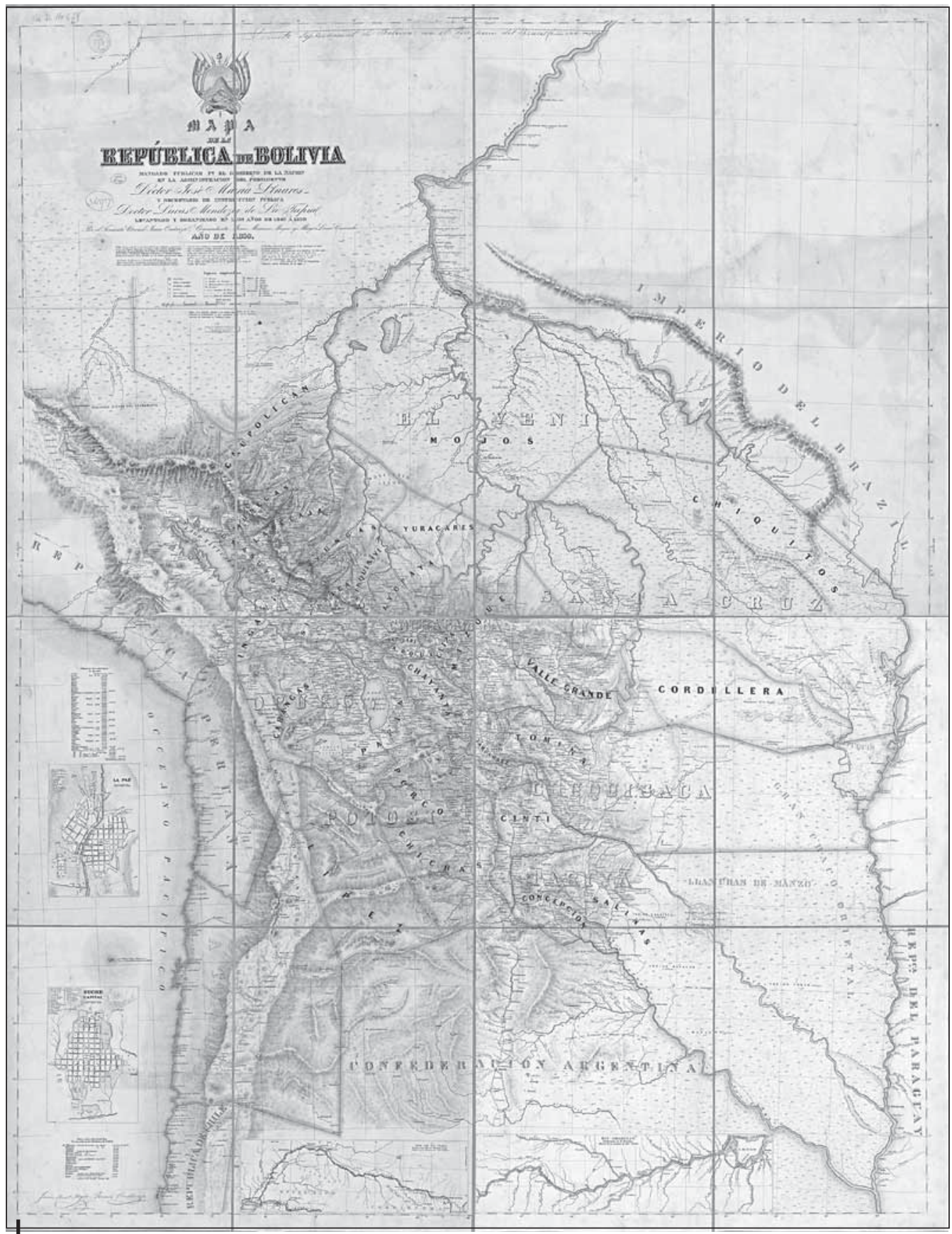

Figura 2 - Mapa Linares, 1859

Fuente http://gallica.bnf.fr/ark:/12148/btv1b530327940 
Después de las pérdidas territoriales, al final de la guerra del Chaco (1935), Bolivia se encuentra con menos de la mitad del territorio que tenía en el momento de su independencia (1825), por lo tanto la conquista de la frontera oriental se convierte en una necesidad nacional para asegurar la supervivencia del país. La frontera interna, que limita la zona realmente ocupada por la sociedad nacional boliviana, tiene que alcanzar la frontera externa, donde se encuentran los límites internacionales del país, para evitar nuevas pérdidas territoriales. A esta necesidad geopolítica de transformar las fronteras orientales vacías en fronteras vivas, se suma la idea que son regiones llenas de recursos naturales. De hecho, desde los Andes, los llanos tropicales donde abunda el agua y no hace frío evocan Eldorado.

El Norte La Paz, más que ninguna otra provincia oriental, personificó esta doble representación de frontera y de Eldorado porque estaba más al alcance de La Paz, el centro político y económico del país (ver fig. 3). Los colonos migrantes, que llegaron a partir de los años 1970 y que siguen llegando hoy en día, fueron atraídos por esta representación (tierras libres por conquistar y abundancia de recursos naturales) y la difundieron. Bernabé Heredia, que vino del Norte Potosí en el 2000, para asentarse en la comunidad del Tigre, a seis horas al norte de Ixiamas, describe su chaco como un paraíso terrestre.

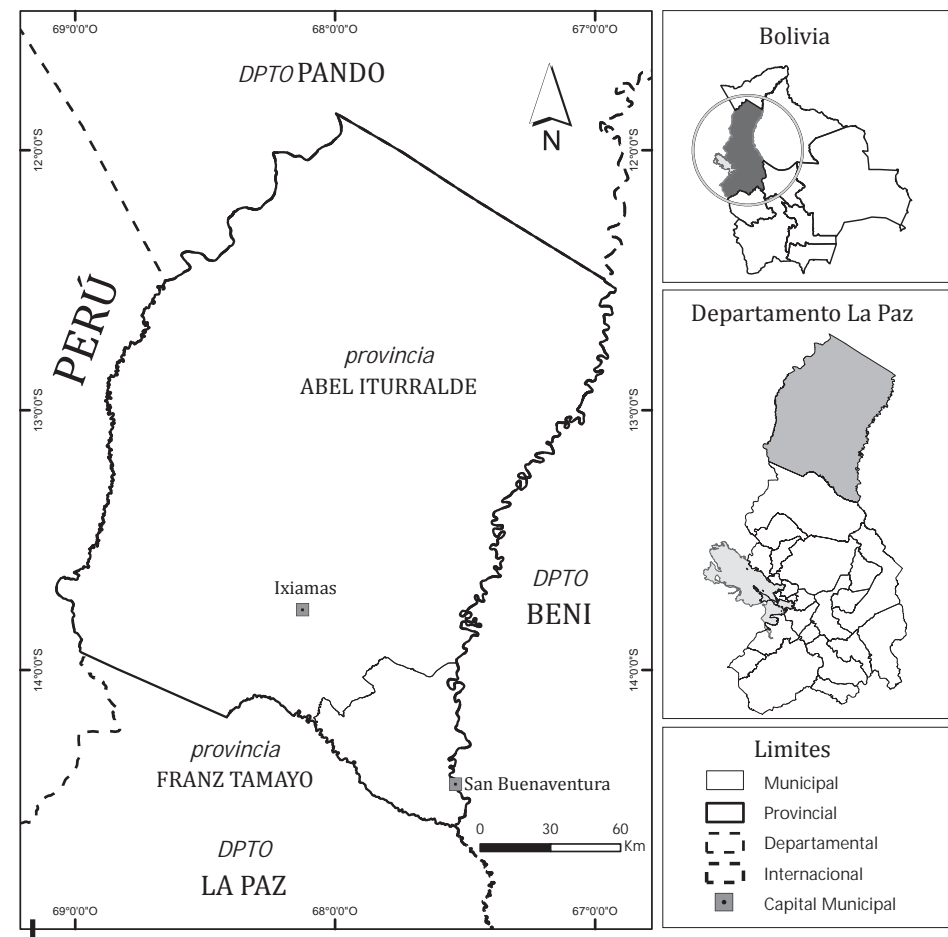

Figura 3 : Ubicación del Norte La Paz

c Laetitia Perrier Bruslé \& Bertha Gozalvez Kreuzer (2015). Cartografía de Marcelo Flores Medrano 
Nosotros criamos chanchos gallinas y lo mejor es tener todo a disposición, tenemos mango, planta, toronja, y luego pasa todo en su época, se acaba la palta ya vienen manga, así rotativo es la fruta (Bernabé Heredia, subgobernador Ixiamas, Ixiamas, 14 de octubre de 2012).

También insiste en la disponibilidad de tierras.

De mis hermanos son 7 y teníamos casi 20 ha [en el Norte Potosí]. Para los

7 y eso es de mi papá, pero la intención de venir aquí era tener terreno propio. Ya que estoy aquí tengo 50 ha titulizados (Bernabé Heredia, subgobernador Ixiamas, Ixiamas, 14 de octubre de 2012).

Todos los colonos que vinieron a poblar el Norte La Paz comparten esta visión de Bernabé Heredia basada en las posibilidades abiertas en esta región.

\section{2. El auge conservacionista en la época de la gobernanza neoliberal}

La integración del Norte La Paz en el entorno nacional tiene un papel estructurante en el imaginario nacional, a pesar de ser más simbólica que efectiva. En una larga escala de tiempo, influyó en las acciones políticas y las estrategias de los migrantes y actores locales. El retorno de la democracia (1982) y la implementación en Bolivia del segundo modelo neoliberal en los años 1990, más creativo que destructivo1, abre un nuevo rumbo integracionista para el Oriente, bajo el paradigma neoliberal y conservacionista. La ruptura con la visión tradicional de la integración es total. El impacto de este paréntesis fue muy fuerte en las relaciones de poder en el Norte La Paz.

Para entenderlo hay que referirse a las bases de este modelo neoliberal. Si bien es cierto que es muy variado en sus expresiones (Perreault \& M artin, 2005), tiene dos bases: la descentralización, para fomentar la democracia y la liberalización de la economía para permitir el desarrollo (Kohl, 2002). Estos dos pilares llevaron a implementar una gobernanza neoliberal del medio ambiente (Bridge $\&$ Perreault, 2009). La idea era cambiar los arreglos institucionales que definían la gestión de los recursos naturales a fin de promocionar las prácticas favorables al mercado. En general, la solución pasaba por el acceso de los actores locales a la propiedad de los recursos naturales (Bridge, 2014). En Bolivia, como en los otros países americanos, el Estado se negó a otorgar el control de las reservas del subsuelo a los indígenas. En cambio los gobiernos neoliberales implementaron una serie de reformas legales para otorgar derechos de gestión sobre los otros recursos naturales a los pueblos indígenas (Fontana \& Gruegel, 2016). Eso se tradujo por la creación de nuevos regímenes de propiedad, en conformidad con los patrones

1 Varios autores insisten en la necesidad de distinguir el neoliberalismo destructivo de Reagan y Thachter (el roll-back neoliberalism) y el neoliberalismo creativo que inventa nuevas formas de regulaciones (el roll-out neoliberalism) (Peck \& Tickell, 2002; Bridge \& Jonas, 2002). 
internacionales en torno a la defensa de los pueblos indígenas (convenio 169 de la OIT de 1989).

En el Norte La Paz, los nuevos regímenes de propiedad tuvieron un fuerte impacto por ser una zona rica en recursos naturales2. La ley de participación popular (1994), la ley del Instituto Nacional de la Reforma Agraria 1715 (1996) y la ley forestal 1700 (1996) abrieron nuevos derechos a los actores locales y le dieron poder en la escena política y económica. Los comunarios colonos así como los grupos indígenas pudieron participar en los gobiernos municipales, titular sus tierras y explotar legalmente el bosque. Pero para gozar de estos nuevos derechos tenían que capacitarse. Las O rganizaciones No Gubernamentales aprovecharon de esta necesidad para entrar en el Norte La Paz, una zona conocida por su alto valor en términos de biodiversidad3. Dieron más poder a los actores locales, sobre todo indígenas, partiendo de la hipótesis que ellos serían los mejores defensores de la naturaleza (Painter et al., 2008). Es así que la nueva gobernanza neoliberal se desarrolló gracias a un juego de escala asimétrico identificado por Peck \& Tickell en otros lugares del mundo:

las instituciones y los actores locales recibieron nuevas responsabilidades sin poder, mientras que las instituciones internacionales y sus actores ganaron poder sin responsabilidades [legalmente reconocidas] (Peck \& Tickell, 2002: 386)4.

Esta asimetría de poder tenía fundamentos espaciales: los primeros, los grupos de actores locales, controlaban, gracias a las nuevas pautas de la gobernanza neoliberal, los territorios locales, mientras que los segundos tenían acceso a la esfera global, donde se encontraban las fuentes de financiamiento necesario para concretizar estos derechos territoriales. La cooperación era imprescindible.

Este momento de encuentro entre las O NG y los actores locales ocurrió a partir de la mitad de los años 1990 hasta la elección de Evo Morales, que cambió las reglas del juego. Para el Norte La Paz ha sido un auge conservacionista. Así lo describe un actor que participó como consultor, entre los años 2000 y 2013, en varios proyectos conservacionistas (para CARE, Allianza O brera Suiza, Helvetas, U said).

En aquella época había una atracción por el Norte de La Paz. Se concentraron las ONG y las cooperaciones internacionales en esta zona

2 Los recursos naturales del N orte La Paz son variados. Primeramente está la madera, cuya explotación empezó en los años 1990, segundamente están las reservas hidrocarburíferas y el potencial enorme en término de hidroelectricidad. Pero el recurso más importante para los colonos es el de las tierras disponibles. El Norte La Paz agrupa más de un cuarto de las 4,4 millones de hectáreas que han sido identificadas por el INRA en 2014 como disponibles por distribuir (sobre 24 millones de tierras fiscales).

3 En 1999, Wildlife Conservation Society, una poderosa ONG conservacionista estadounidense, atribuyó a la zona del Madidi el título de «Gran Paisaje». Es un testimonio del interés mundial por esta zona.

4 In the asymmetrical scale politics of neoliberalism, local institutions and actors were being given responsibility without power, while international institutions and actors were gaining power without responsibility. 
de alto valor ecológico. Y como había muchos consultores, los proyectos naturalmente se concentraron donde existía una fuerza de trabajo para armarlos. A nosotros, los consultores, nos gustaba la ciudad, y siempre había nuevos trabajos, nuevas consultorías etc. [... ] (Yvette Carrasco, directora del Proyecto Amazonía Integral en Rurrenabaque-USAID, 2/10/2012).

Durante el auge, se multiplicaron las zonas de preservación y los territorios indígenas. Las ONG trabajaron tanto con los colonizadores como con los indígenas, pero su nivel de implicación fue más importante con estos últimos, a quienes dedicaron mayor energía. Esta preferencia se explica de varias maneras. Primeramente, las ONG encontraron fuentes de financiamientos fáciles para trabajar en esta zona, destacada a nivel mundial por su alto valor ecológico. Segundamente los grupos indígenas podían recibir, según la ley, territorios mucho más grande, lo que permitía implementar una política ambiciosa de gestión y protección de los recursos naturales. Terceramente, los indígenas eran los más afectados por el proceso de integración y de explotación desregulado de las regiones orientales que se amplificó a partir de los años 1980. La marcha por el territorio y la dignidad en 1990 fue una voz de alarma. Las amenazas que pendían sobre los grupos indígenas del 0 riente eran fuertes y bien mediatizadas. Es por eso que las $\mathrm{ONG}$ apoyaron en prioridad estos grupos sociales vistos como más frágiles.

\section{3. El desafío neodesarrollista en la época del retorno del Estado}

La elección de Evo Morales en 2005 llevó a una reconfiguración de los modelos de gobernanza. El desafío de impulsar un proceso de cambio profundo llevó al gobierno de Evo Morales a buscar los caminos de un modelo «posneoliberal». Había que inventarlo en gran parte, sabiendo que era difícil abandonar algunos de los derechos adquiridos en el periodo anterior que habían abierto nuevos espacios políticos y económicos para varias clases de actores sociales (H aarstad \& Anderson, 2009; Lavaud, 2007; Postero, 2007).

En Bolivia, como en Ecuador, la relación de la sociedad con los recursos naturales se volvió central en la invención de este nuevo modelo postneoliberal5 (Bridge, 2014: 126).

El modelo neoextractivista restablece el Estado en el centro de los procesos económicos, mediante su capacidad de movilización de los recursos naturales (Bebbington, 2012; Kaup, 2010). Al paradigma neoliberal de crecimiento liderado por las exportaciones de materias primas se añaden algunos mecanismos de redistribución social (Gudynas, 2012; Grugel \& Riggirozzi, 2012). En otros términos, el desarrollismo económico, basado en la explotación de los recursos naturales, y el centralismo político son los dos pilares del «proceso de cambio» impulsado por el gobierno de Evo Morales. El indigenismo, el autonomismo, el

5 Bolivia and Ecuador, for example, have explicitly positioned the relationship to natural resources as central to a post-neoliberal development model. 
«pachamamismo» (o sea la protección del medio ambiente) y el plurinacionalismo que deberían caracterizar a Bolivia, según la nueva constitución política de 2009 (Estado Plurinacional de Bolivia, 2009), no son por el momento muy operativos. La gobernanza local y la conservación de la naturaleza no son la prioridad de un Estado que quiere restaurar su autoridad (Tockman \& Cameron, 2014). El deseo de construir a pesar de los costos sociales y ambientales una carretera a través el Tipnis (parque natural y territorio indígena) demuestra el giro político del gobierno (Stefanoni \& Saint U péry, 2011; Perrier Bruslé, 2012; Calla, 2011). El retorno del Estado se traduce también en el reforzamiento de la escala nacional como espacio de acción política y de poder, y por el retroceso de las redes de poder que vinculaban lo local a lo global6. En realidad, esta alianza ONG-actores locales se está debilitando en Bolivia, porque los dos perdieron mucho poder a partir de 2008. Las O NG sufren una disminución de su margen de maniobra mientras que varios grupos indígenas del Oriente se alejaron del gobierno por su orientación centralista, autoritaria y extractivita (Andreucci \& Radhuber, 2015; Tapia M ealla, 2014).

El hecho que el modelo posneoliberal en Bolivia tenga un enfoque principal sobre los recursos naturales, puso otra vez al Norte La Paz bajo los proyectores de la actualidad. Esa región rica en recursos naturales, cerca del poder político central, menos sospechosa de disputas autonomistas que los departamentos orientales (Beni, Santa Cruz y Pando), fue elegida como zona testigo para implementar el neoextractivismo. El gobierno de Evo Morales implementó varios megaproyectos en la zona: planta azucarera, exploración hidrocarburífera, construcción de la carretera San Buenaventura-Ixiamas para abrir la frontera Norte, distribución de tierras fiscales (Laats, 2011; Perrier Bruslé \& Gosalvez, 2014). O tros proyectos regresan a la agenda política, como la represa hidroeléctrica del Bala en el río Beni, aguas arriba de Rurrenabaque.

Estos megaproyectos impulsados por el Estado abren un nuevo capítulo en la larga historia de integración del Norte La Paz en el territorio boliviano. Pero en varios aspectos este nuevo rumbo integracionista adopta las antiguas representaciones de la región como frontera y como El Dorado. Las dos representaciones son relacionadas en la medida que la conquista de la frontera tiene como motor la figura de El Dorado proyectada sobre la región vista como llena de recursos. Esta conquista de la frontera implica que el Norte La Paz debe servir al desarrollo del país entero. Para eso la región debe ser integrada en el territorio nacional abandonando sus características propias. Esta figura de la frontera vuelve a ser muy presente en los discursos oficiales. La candidata plurinominal por La Paz, Andrea Bonilla (M AS-IPSP) se apoyó por ejemplo en esta doble visión de frontera y de El Dorado cuando ella sostuvo que el Norte La Paz

esa región tropical tiene un potencial enorme en producción agrícola, pero también minera y petrolera, que debe ser explotada para beneficio de la población boliviana (Cori, 2014).

6 Sobre las estrategias espaciales y escalares de los actores sociales ver los enfoques teóricos de varios autores (Neumann, 2009; Jones, 1998). 
Bolivia: el nexo saber-poder en las reconfiguraciones de un margen en proceso de integración

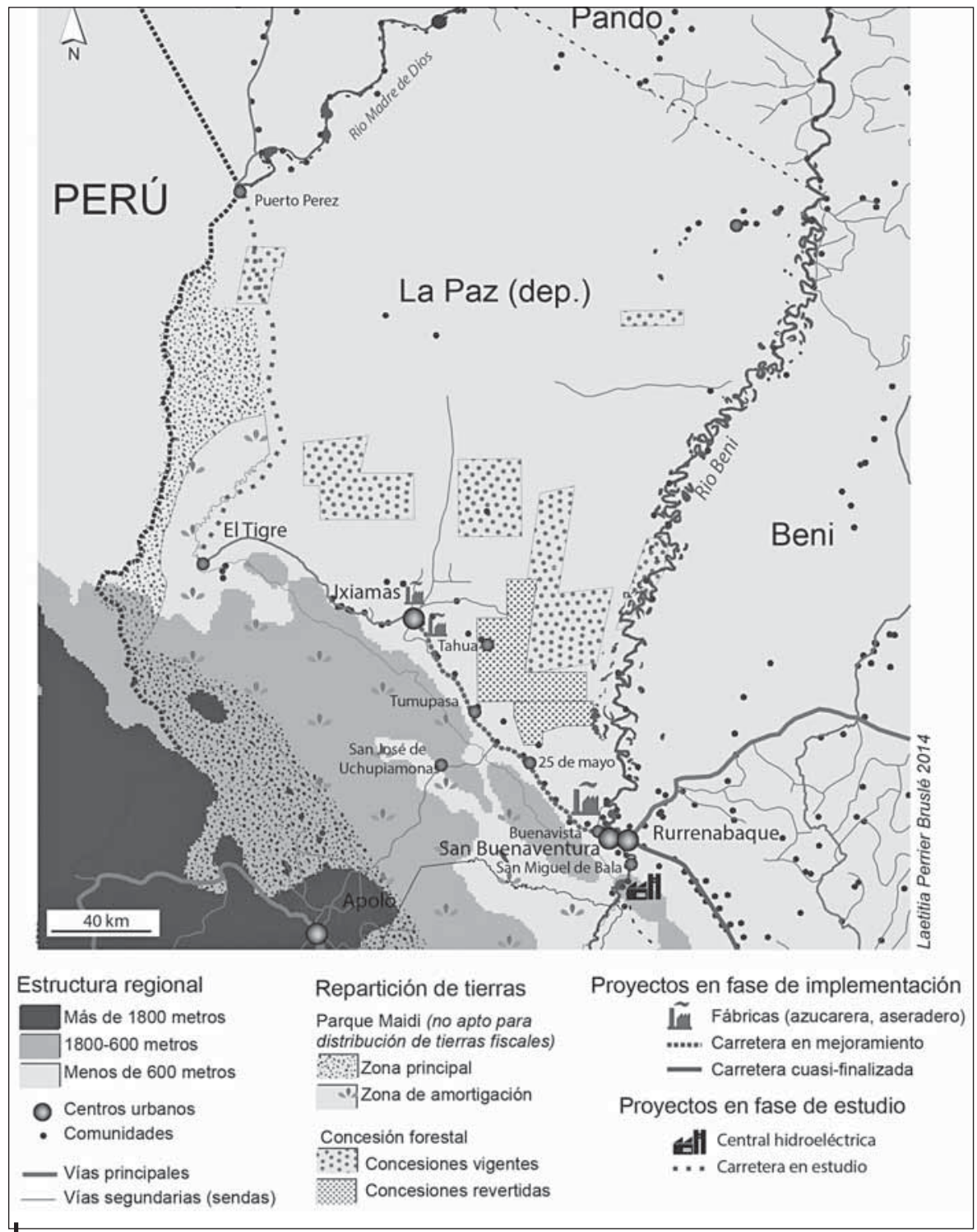

Figura 4 - Los megaproyectos de Evo Morales para el Norte La Paz

Mientras García Linera, el Vicepresidente, frente al concejo municipal de La Paz afirmó en julio de 2014 «La Paz [el departamento] no puede rezagarse, debe mantener el liderazgo para ser el bastión de unidad y desarrollo del país» y señaló que en «el ámbito productivo, esta región, además de potenciar el altiplano, debe volcar su mirada en el norte de La Paz» (Cambio, 2014). En octubre de 2015, el gobierno decidió dedicar una parte del préstamo chino (7500 millones de dólares) 
para la construcción de la carretera Apolo-Tumupasa-Ixiamas-Chivé-Cobija. Este megaproyecto permitirá abrir más allá de Ixiamas el avance de la frontera hacia el norte. Esta obra, junto con dos otras megacarreteras, permitirá «cumplir un sueño y una obligación boliviana desde su fundación, integrar la Amazonía hacia los valles y el altiplano», como lo decía Alvaro García Linera en esta oportunidad (Vale, 2015). Es así que la idea de aprovechar y conquistar la frontera N orte sigue vigente en la mente como si nada hubiera cambiado desde que Cordepaz', en los años 1970, abrió «la marcha hacia la frontera norte». El retorno de esta visión de frontera muestra que, más allá de las alianzas entre lo global y lo local, la escala nacional se impone en la época actual como única fuente de legitimación de la acción política. La integración nacional de las periferias orientales vuelven a ser prioritarias y el horizonte político es el territorio nacional.

\section{4. Conflictividad y nuevos focos de poder en el Norte La Paz}

Cada etapa de integración llevó a una reconfiguración de los poderes a escala local. En la época conservacionista los actores indígenas se empoderaron, mientras la nueva etapa de integración da más poderes a los inmigrantes de otras regiones de Bolivia que están pidiendo tierras fiscales con el apoyo del gobierno8. Estas reconfiguraciones sociales explican el alto nivel de conflictividad en la región del Norte La Paz. En septiembre de 2009, los indígenas tacanas se enfrentaron con los colonos llegados en los años 1970, llamados interculturales, a propósito del destino de 80000 ha de tierras fiscales de una ex concesión forestal (Fundación TIERRA, 2011; Ströher, 2013). En noviembre de 2013, el Consejo Indígena del Pueblo Tacana (Cipta, a la cabeza de la TCO Tacana 1) con el respaldo de la Federación de Interculturales de Abel Iturralde (Fespai), amenazó a Fernando Choque, secretario ejecutivo de la Federación Departamental de Trabajadores Campesinos de La Paz «Túpac Katari» de recurrir a la justicia comunitaria, porque el Gobierno dotó [entregó?] 180000 ha para los campesinos de esta organización (Erbol, 2013a; 2013b). La multiplicación de los conflictos sociales demuestra que los espacios de poder han ido multiplicándose en el Norte La Paz, conforme a los análisis de Michel Foucault que planteaba la necesidad de identificar los focos moleculares de poder resultantes de estrategias individuales, más allá de la visión sencilla de un poder estatal monopolístico (Foucault, 2008a).

La relación entre dinámica de integración al entorno nacional y global, nuevas redes de poder y conflictividad empeorada es cierta. Se sustenta en los mecanismos internos que permiten a los individuos adquirir más poder. Cada grupo de actores

7 Cordepaz: Corporación de desarrollo del departamento de La Paz fundada en 1971. Fue una de las corporaciones regionales de desarrollo que se implementaron entre 1950 y 1990, y sobre todo durante el periodo de los gobiernos militares (1964-1971) (Arze Cuadros, 2002).

8 Los términos de «tierras fiscales» sirven para definir las tierras que pertenecen al Estado porque no fueron todavía distribuidas. 
sociales tiene espacio de legitimación e instrumentos de poder diferentes. La pequeña élite de la población urbana se apoya en sus redes comerciales hacia afuera y su acumulación capitalista así como sus buenas relaciones con el MAS para adquirir nuevas tierras en el Norte La Paz, mediante la creación de comunidades campesinas. La élite tradicional asegura su poder mediante el control de las redes políticas locales y sus propiedades agrarias de ganadería (finca), los indígenas se afirman como nuevo centro de poder mediante el control de grandes extensiones de tierra en el marco de las Tierras Comunitaria de O rigen (TCO) y sus conexiones con redes conservacionistas mundiales. Por fin, los grupos de colonos interculturales gozan de su control de los espacios de poder local (en los municipios) y de su ocupación material de la tierra para hacer valer su posición.

\section{Cuadro 1 - Instrumentos de poder, redes y espacio de legitimación}

\begin{tabular}{|c|c|c|c|}
\hline & Instrumentos de poder & Redes de poder & \begin{tabular}{|l|} 
Espacio de \\
legitimación
\end{tabular} \\
\hline $\begin{array}{l}\text { Pequeña élite urbana } \\
\text { procedente de los } \\
\text { Andes (comerciantes, } \\
\text { transportistas, etc.) }\end{array}$ & $\begin{array}{l}\text { Acumulación } \\
\text { capitalista en actividad } \\
\text { de comercial y } \\
\text { servicios en los centros } \\
\text { urbanos del NLP }\end{array}$ & $\begin{array}{l}\text { Relaciones con } \\
\text { los centros de } \\
\text { poder nacionales } \\
\text { (mediante Túpac } \\
\text { Katari-CSTUCB) }\end{array}$ & Nacional \\
\hline $\begin{array}{l}\text { Élite tradicional } \\
\text { ganadera procedente } \\
\text { del Oriente }\end{array}$ & $\begin{array}{l}\text { Grandes extensiones } \\
\text { de tierras }\end{array}$ & $\begin{array}{l}\text { Hasta los años } \\
\text { 2000: fuerte } \\
\text { presencia en las } \\
\text { instancias de poder } \\
\text { local }\end{array}$ & $\begin{array}{l}\text { Local/Regional } \\
\text { (hacia el Beni) }\end{array}$ \\
\hline $\begin{array}{l}\text { Indígenas con TCO } \\
\text { titularizadas }\end{array}$ & $\begin{array}{l}\text { Control de grandes } \\
\text { extensiones de tierras }\end{array}$ & $\begin{array}{l}\text { Relaciones con las } \\
\text { O NG (sociedad } \\
\text { civil global) }\end{array}$ & Global \\
\hline $\begin{array}{l}\text { Colonos interculturales } \\
\text { llegados desde los años } \\
1970 \text { (afiliados a la } \\
\text { Fespai) }\end{array}$ & $\begin{array}{l}\text { Control material de la } \\
\text { tierra }\end{array}$ & $\begin{array}{l}\text { Presencia de los } \\
\text { órganos de poder } \\
\text { local (municipios) }\end{array}$ & Local \\
\hline
\end{tabular}

Para asegurar estos espacios de legitimación y sus instrumentos de poder, los actores sociales utilizan los saberes y la información. Es así como el mecanismo que permite ganar poder está ligado a la cuestión de los saberes. En las dos próximas secciones demostraré que el nexo poder-saber funciona como un mecanismo interno de empoderamiento. Me apoyaré en el concepto de poder tal como lo plantea Michel Foucault, así como en la noción de capacidad de Amartya Sen (Sen, 1999a; 1999b). M ostraré de manera dialéctica que si la información permite acceder a nuevos poderes (segunda parte), estos poderes producen saberes (tercera parte). Esta relación poder-saber es crucial para entender cómo actores locales pueden escapar a una marginalidad social o territorial. 


\title{
2. EL ACCESO A LA INFORMACIÓN EN EL EMPO DERAMIENTO DE LOS ACTO RES
}

\author{
2. 1. La capacidad territorial clave para desarrollar funcionalidades \\ en el Norte La Paz
}

El poder de los actores en el Norte de La Paz depende de su capacidad territorial. Esta noción deriva del concepto de capacidad propuesto por Amartya Sen a partir de los años 1980 para medir la calidad del desarrollo, más allá de los indicadores económicos (Sen, 1985; 1992; 1999a). Sen afirma que las capacidades de cada actor dependen de sus oportunidades para desarrollar sus funcionalidades, es decir ser alguien y actuar (comer, trabajar, estar sano o en un plano más complejo estar feliz, tener autoestima, etc.)9. La combinación de capacidades permite a cada actor alcanzar el bienestar. Lo importante es que las capacidades estén ligadas al poder que cada actor tiene sobre los recursos (las habilitaciones) y también sobre su propia vida - el poder de elegir el conjunto de funcionalidades que mejor le corresponde (Cejudo Cordoba, 2007; N ussbaum, 2003; Robeyns, 2011)—.

Sen siempre subrayó la dificultad de establecer una lista canónica de las capacidades indispensables para el ser humano. Primeramente porque depende de cada contexto, segundamente porque cada sociedad tiene que definir, mediante un debate público, las capacidades que deberían ser consideradas como fundamentales (Sen, 2005). Siguiendo este punto de vista, podemos destacar cuáles son las capacidades fundamentales en el mismo contexto del Norte de La Paz. El trabajo de campo nos enseñó que dentro de estas capacidades, es clave la que está ligada al territorio. Permite a los actores desarrollar sus funcionalidades dándoles más poder para enfrentar y adaptarse a los cambios. Esta capacidad territorial se expresa, según los resultados de nuestra encuesta, en dos campos. Primero, en el campo político, la capacidad territorial da la posibilidad de desarrollar varias funcionalidades: participar en las instituciones representativas, expresarse y asociarse para lograr objetivos políticos y, por último, alcanzar escenarios políticos en varias escalas (nacional y global). Segundo, en el campo material, la capacidad territorial se traduce en varias funcionalidades: ser dueño de su tierra, encontrar trabajo, acceder a los recursos naturales, entre otras. Esta capacidad territorial, tal como se desarrolla en estos dos campos, da más poder a la gente. En el camino de entrada hacia cada comunidad tacana, en la TCO manejada por el Cipta (Consejo Indígena del Pueblo tacana) se puede ver un letrero que indica «se prohíbe el ingreso de personas ajenas a la TCO Tacana sin permiso de la organización» (fig. 5).

La presencia de este letrero podría mostrar que los indígenas tacanas se sienten amenazados en su control territorial, por lo cual podríamos pensar que este control es débil. Las entrevistas hechas con los dirigentes de la TCO nos conducen

9 The idea of 'capability' is the opportunity to achieve valuable combinations of human functionings what a person is able to do or be (Sen, 2005: 153). 


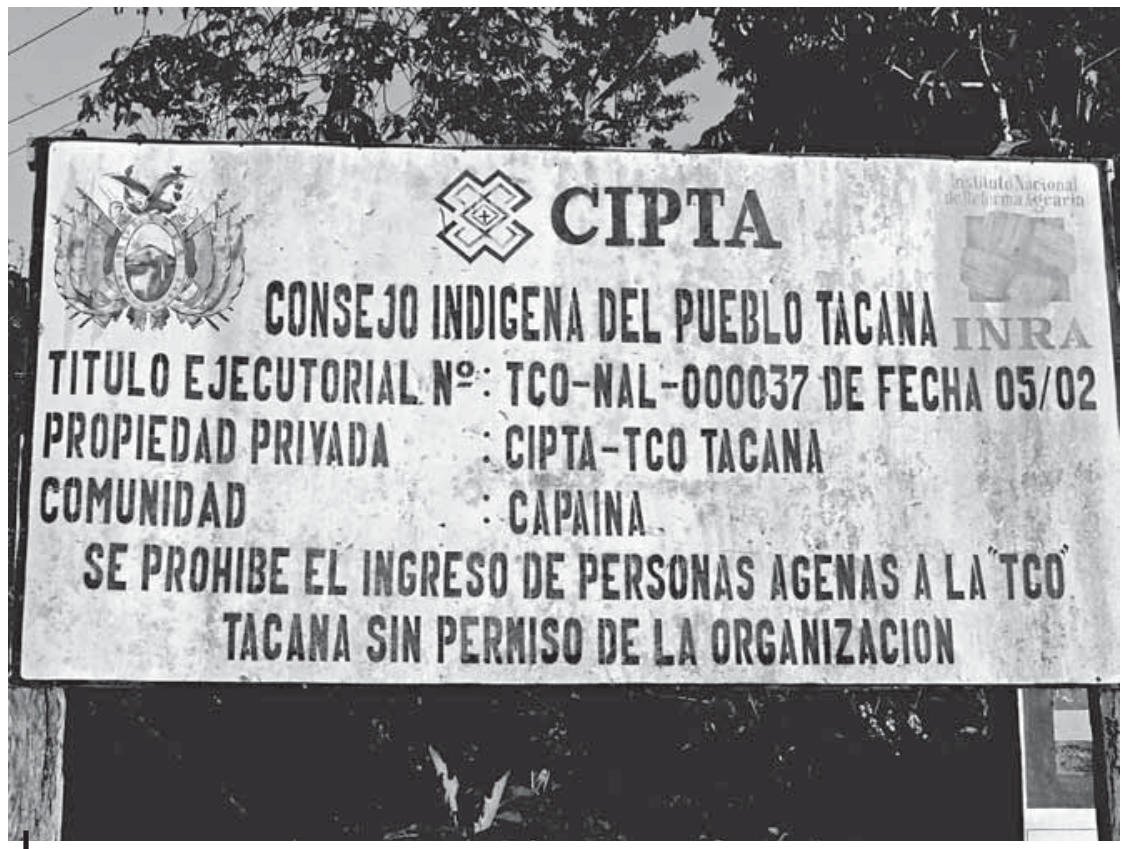

Figura 5 - Panel ubicado en la entrada de la comunidad Capaina dentro de la TCO tacana. Un fuerte control territorial

(c) L. Perrier Bruslé, 28 de septiembre de 2012

a interpretar lo más como una demonstración de fuerza. Estos letreros inscriben en el terreno la realidad del poder territorial adquirido por los indígenas gracias a la titulación de su TCO. Cuando el secretario de Recursos Naturales del Cipta nos presentó los reglamentos internos aplicables sobre el acceso a los recursos naturales dentro de la TCO 10, decía que eran tan difíciles de hacer cumplir como las leyes del Estado. Esta comparación, que pone en posición de igualdad las leyes estatales y las que son definidas por el Consejo Tacana, indica la fuerza del control territorial de los indígenas tacanas que se apoya en la certeza de ser los legítimos dueños del lugar. Según la visión del ejecutivo del Cipta el Estado es tan importante como el consejo tacana, cuando se trata de definir las regulaciones sobre los recursos naturales en la TCO. Más allá, en la misma entrevista, el secretario de Recursos Naturales del Cipta, llegó incluso a hablar del «autogobierno tacana». Eso demuestra la convicción anclada en las autoridades del Cipta de controlar su territorio, así como la voluntad de demostrar a los extranjeros este control.

Es un desafío para nosotros como organización hacer que en nuestro territorio tengamos un autogobierno. Tenemos que cumplir las propias normas y que las comunidades sean partícipes de su propia elaboración,

10 Hacía referencia al «Reglamento de acceso, uso y aprovechamiento de los recursos naturales renovables del territorio indígena takana» editado en 2008 (Cipta et al., 2008). 
sabemos que tenemos algunas dificultades pero en lo posible tratamos de cumplir (Marcelo Marupa, Secretaria de Recursos Naturales del Cipta, Tumupasa, oficinas del Cipta, el 02/05/2013).

Esta evocación del autogobierno demuestra cómo la capacidad territorial, más allá de permitir desarrollar funcionalidades básicas, abre un nuevo espacio de poder a nivel local. Es un espacio dinámico que siempre debe ser defendido, negociado, todo lo contrario de un poder adquirido de manera permanente.

\section{2. Los saberes fortalecen la capacidad territorial}

La capacidad territorial, concebida como una fuente de poder, se ha reforzado en la última década en el grupo testigo de los tacanas que hemos analizado. Para entenderlo tenemosque entrar en el mismo mecanismo que genera esta capacidad. Nuestra hipótesis es que los saberes son determinantes en la constitución y el fortalecimiento de la capacidad territorial. De hecho esta capacidad se nutre de dos parámetros fundamentales: la seguridad jurídica sobre los recursos (tierra, territorio, bosque etc.) y el nivel de acceso a la información. Estos dos parámetros son interdependientes en el sentido que el primero, la seguridad jurídica, depende del nivel de información que determina el conjunto de saberes.

Esta seguridad jurídica sobre los recursos es central en la teoría de Sen. Según él, no son los recursos los que importan sino la posibilidad que tienen los actores de acceder a estos recursos. Es decir lo que otorga una capacidad son los recursos

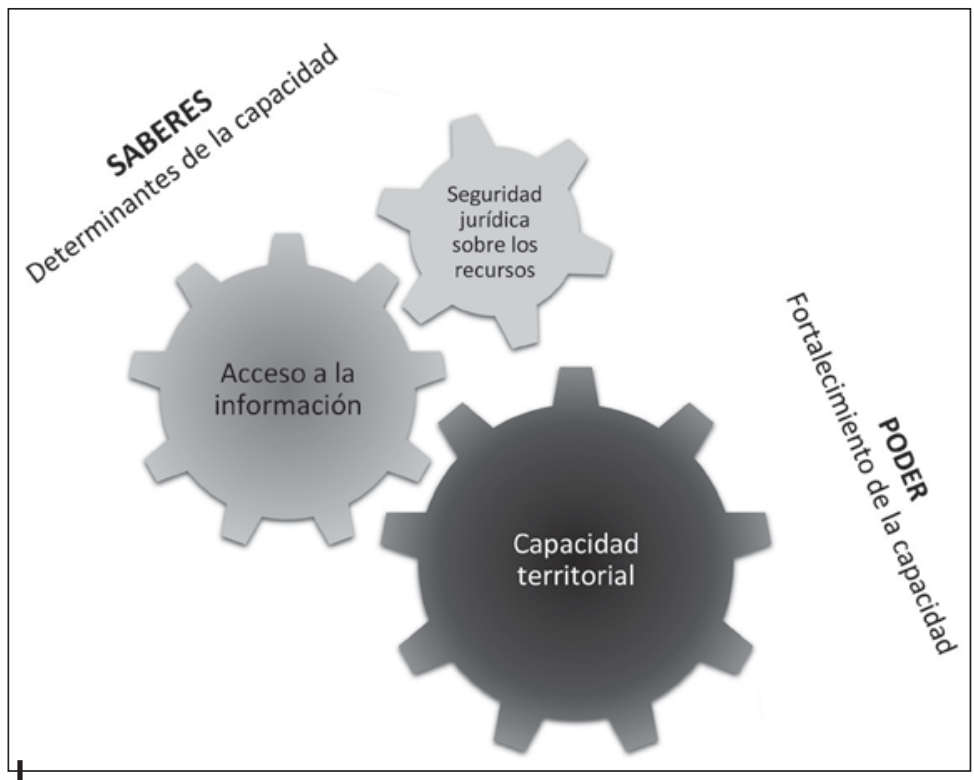

Figura 6 - Capacidad territorial, acceso a la información y seguridad sobre los recursos: esquema de la relación saber-poder en el Norte La Paz

๑ Laetitia Perrier Bruslé, 2015 
que están bajo el poder del sujeto (Sen, 1981)11. Sen usa el término de entitlement en inglés para traducir esta relación de poder que corresponde al término de habilitación en castellaño «en el sentido de dar derecho a algo» (Cejudo Cordoba, 2007: 11). En el Norte de La Paz, las habilitaciones fundamentales fueron concedidas por el Estado neoliberal cuando reconoció la necesidad para los colonos y los indígenas de gozar de una seguridad jurídica sobre la tierra, así como cuando les dio la posibilidad de hacer uso de los recursos naturales (recursos maderables sobre todo). El marco jurídico planteado por la ley 1715 (1996), conocida como la ley INRA, condujo al saneamiento de las tierras del Norte La Paz entre 2000 y 2005. De los 4 millones de hectáreas del N orte La Paz, aproximadamente 400000 se titularon para el sector indígena, bajo el régimen de las TCO y 450000 para el sector de las comunidades de interculturales así como la pequeña y mediana empresa agrícola (entrevista con Víctor Espinal, Director de Distribución de Tierras, La Paz, el 10/10/2014). En total, casi un cuarto de las tierras pasaron al control de los sectores campesinose indígenas, garantizando una fuerte capacidad de los actores locales de regulación de los recursos naturales. Es así que se consolidaron sus capacidades territoriales y finalmente su poder.

Pero todo el proceso de titulación de tierras y la gestión misma de las tierras requieren hoy en día el manejo de mucha información. Es por eso que el segundo determinante de la capacidad territorial, el acceso a la información, se ha vuelto central. Las mismas habilitaciones, según la teoría de Sen, dependen de un buen nivel de información. Cuando lucharon por titularizar sus tierras y asegurar su acceso a los recursos naturales, los indígenas tacanas del Cipta, así como los interculturales/colonos de la Fespai, se apoyaron en redes que les facilitaron el acceso a la información sobre sus derechos territoriales y la manera de hacer valer estos derechos. Algunas redes pasaron por las instituciones representantes nacionales (Cidob12, $\mathrm{CSClOB13),} \mathrm{pero} \mathrm{también} \mathrm{por} \mathrm{las} \mathrm{ONG} \mathrm{que} \mathrm{conocían} \mathrm{los}$ procesos de titulación. Wildlife Conservation Society (WCS) apoyó por ejemplo la titulación de la TCO Tacana I. El acceso a la información es crucial para conocer los marcos legales, y también es fundamental para aumentar sus capacidades.

Primero la información permite enterarse de las oportunidadeseconómicas creadas por los nuevos proyectos (implantación de empresa, proyectos camineros). Un caso demostrativo es el de una familia de colonos recién llegados de Cochabamba (una pareja con dos niños de corta edad). Sin recursos económicos, ellos se habían asentados en el borde del camino de Ixiamas a El Tigre, algunos kilómetros fuera de la comunidad de San Pedro. Se encontraban allí desde hace menos de seis

11 Sen, para hacer entender la importancia de las habilitaciones, decía que una persona podía morir de hambre en un país donde sí había comida. Lo importante no era la disponibilidad del recurso pero la posibilidad de acceder a el (Sen, 1981).

12 Cidob: Confederación de Pueblos Indígenas de Bolivia, que representa a los pueblos indígenas de las Tierras Bajas de Bolivia para defender sus derechos.

13 CSCIO B: Confederación Sindical de Comunidades Interculturales de Bolivia. Es la organización matriz de los colonizadores del O riente boliviano que decidieron llamarse interculturales porque el término colonos era peyorativo. 
meses. Al preguntarles sobre sus objetivos y la razón de su instalación, M ario Cosio Vilaruel, el jefe de familia, respondía «porque quiero sembrar caña para venderla al ingenio de San Buenaventura» (Comunidad San Pedro, el 12 de septiembre de 2013)... lo que no era posible porque la zona de recolección de la caña no puede superar una distancia de $60 \mathrm{~km}$ desde el ingenio. Ellos estaban asentados a más de 120 km. En este caso la falta de información explicaba su baja capacidad territorial e iba a dificultar el desarrollo de sus funcionalidades.

La información también permite enterarse de los recursos naturales disponibles; por ejemplo saber sobre las tierras fiscales que podrían ser distribuidas es fundamental. El Norte La Paz es una de las provincias de Bolivia con la mayor cantidad de tierras fiscales (1,2 millones de hectáreas sobre los 4,4 millones de hectáreas de tierras fiscales disponibles en Bolivia)14. Esta reserva de tierras viene a ser un desafío clave de alcance nacional más allá de la misma provincia del Norte La Paz. Víctor Espinal, Director de Distribución de Tierras en el INRA nacional, nos afirmaba que actualmente debe haber más de 300 solicitudes de creación de comunidades en el Norte La Paz (entrevista personal el 10/10/2014). La Fespai (sindicato de los interculturales de la provincia Abel Iturralde), la Túpac Katari (de los colonos recién llegados afiliados al sindicato campesino nacional CSUTCB15, confiable aliado del gobierno) y el Cipta (de los tacanas) luchan por obtener la mayor información posible sobre el destino de las tierras fiscales disponibles, por ejemplo las de la ex concesión forestal Proinsa (Ströher, 2014) o para conocer los avances del proyecto legislativo de desmovilización de tierra en Abel Iturralde - desde 1991 la provincia Abel Iturralde ha sido declarada como área de inmovilización de tierras (DS 23022 modificado en 2000 con el DS 25675)—. Estas organizaciones se vinculan con la Vicepresidencia o el Viceministerio de Tierras para aumentar su poder local.

La información puede también servir para conocer lascondiciones de los mercados o para entender las dinámicas ambientales (evolución del suelo, preservación del equilibrio ambiental, etc.). Un estudio sobre el desarrollo del cacao silvestre en la provincia Abel Iturralde demostró que las comunidades involucradas en esta producción necesitaban acceder a nuevas redes de información para cumplir con las normas exigentes de esta producción certificada (Krings, 2014). Toda la capacidad territorial depende al final de la habilidad de informarse, en un mundo interconectado y polinuclear donde el Estado ya no tiene el monopolio de generar información espacial, como el Estado fuerte y autoritario de hace veinte años atrás (Scott, 1998).

14 En 2014, el INRA afirmó que 4,4 millones de tierras fiscales estaban pendientes para dotación. De esta cantidad de tierras fiscales disponibles, el departamento de Santa Cruz concentra 1,6 millones de hectáreas ( $36 \%$ de las reservas disponibles), la provincia Abel Iturralde, que corresponde al Norte de La Paz, 1,2 millones (27\%) y el departamento del Beni con más de un millón de hectáreas (24\%) (Corz, 2014; Menacho, 2014).

15 Confederación Sindical Única de Trabajadores Campesinos de Bolivia. 


\section{3. ¿CÓMO EL PODER PRODUCE SABERES?}

\section{1. Relación dialéctica, ejercicio del poder y producción de saberes}

Las situaciones de empoderamiento que hemos encontrado en el Norte de La Paz nos obligan a ir más allá de un análisis básico donde la información sirve únicamente para construir y fortalecer una capacidad territorial, fuente de poder. En realidad los poderes son una instancia de producción de saberes porque se apoyan mutuamente. Si bien este análisis se enraíza en los estudios del nexo poder-saber de Foucault, surgió más bien como una intuición en el transcurso de nuestro trabajo de investigación. En diciembre de 2012, participé, con otros dos investigadores del proyecto Capaz, en una reunión del Consejo Indígena del Pueblo Tacana (Cipta). La meta de esta reunión era presentar los objetivos de nuestro proyecto de investigación y llegar a un acuerdo con el Cipta para desarrollar el trabajo de campo en el territorio Tacana (TCO Tacana I). La capacidad territorial de este pueblo es fuerte. Su convicción de ser dueños del territorio está profundamente anclada. Por eso reivindican el derecho de regular la presencia de los foráneos. Lo que nos sorprendió, más allá de este poder territorial, es el interés que ellos tenían en el resultado final del proyecto: la publicación de un libro colectivo sobre las reconfiguraciones de los actores sociales en la región. El vicepresidente del Cipta pidió a los investigadores revisar el libro antes de su publicación y solicitó que esta institución apareciera como coautor del libro. Su argumento fue el siguiente:

Existen varias culturas en la región. No podemos permitir que se escriba algo que podría volverse contra nosotros (...) En el caso de su libro necesitamos ver la publicación final y aparecer como autores porque se trata de nuestra cultura (...) Somos una TCO eso nos simplifica la vida pero somos celosos. Siempre apuntamos a este territorio Tacana (Giovanni Delgadillo, vicepresidente CIPTA, 12 diciembre 2012, Tumupasa).

Este interés en la producción de conocimientos científicos nos demuestra la relación dialéctica entre el ejercicio del poder y la producción de saberes. El poder de los tacanas se concretiza en su alto control territorial. Pero para asentarlo, es necesario apoyarlo sobre saberes que se convierten en discursos de legitimación del poder. En esta misma reunión, el directorio del Cipta nos mostró los libros publicados sobre su pueblo publicado con su autorización16. Esto revela la

16 De hecho la mayoría de los libros e informes sobre la TCO tacanas mencionan al Cipta, o su presidente, como autor principal. Los otros autores, consultores contratados por las O NG, aparecen como segundos autores redactores o como redactores. En el caso de nuestro trabajo hemos rechazado la idea de dar al pueblo tacana, que fue encuestado como los otros grupos de actores sociales del Norte La Paz, el título de autores... porque no correspondía a la geometría de un trabajo donde ellos fueron los encuestados. Gracias a las entrevistas que hemos realizado con ellos hemos podido llegar a un análisis de las dinámicas sociales en el N orte La Paz. Pero jamás fueron los productores de este análisis. 
relación que ellos establecen entre su poder territorial y la necesidad de controlar los saberes producidos sobre ellos. De cierta manera, el marco jurídico planteado por la gobernanza neoliberal (sobre todo el de la ley INRA de 1996) les obligó a establecer esta relación poder-saber. En efecto, la ley consideraba otorgar tierras comunitarias de origen solamente a los pueblos que demostraban su identidad indígena. En otras palabras, como lo subrayó Enrique Herrera a propósito de los tacanas del Beni, «la nominación étnica fue un aspecto fundamental en el reconocimiento de sus derechos territoriales» (Herrera Sarmiento, 2009: 158).

Pero si el marco jurídico neoliberal tuvo un peso en la conformación de esta relación saberes/identidad/poder territorial, el nexo perduró más allá de la titulación de las tierras. Es que el poder para perdurar tiene que producir saberes que lo legitimen. Estos saberes pueden ser producidos de manera propia. Pero en el caso Tacana fueron mediatizados por actores externos, consultores de O NG por lo general, que dominaban más el campo escrito en el cual se fijaban los saberes. Al final se imponen como un discurso de verdad para la sociedad más allá de la esfera tacana. El hecho que los numerosos documentos escritos sobre los tacanas fueran cofirmados por los autores originales y los representantes del pueblo tacana demuestra que la apropiación es total. Las autoridades tacanas se consideran, dando su poder territorial, como productores de saberes, a pesar de haber participado poco, por lo general, en el proceso mismo de redacción.

Para entender este proceso de transferencia es necesario partir de la hipótesis de Foucault según la cual el poder es siempre relacional. El poder no pertenece a una sola institución, el Estado, tampoco tiene un solo lugar. El poder es inmanente al campo social y se disemina en una constelación de focos en todas las escalas (Olivier, 1988). Por eso, la cuestión central en torno al poder ya no es su apropiación por una sola entidad, menos la relación Estado-poder, sino su producción (Foucault, 1976)17. En el dispositivo de producción del poder, el saber es central. Es una fuente de legitimación del poder necesaria porque el poder no tiene un solo modo operativo (la represión y la interdicción) y no puede ejercerse solamente con violencia. Foucault decía en una entrevista famosa en 1975

si el poder se ejerciera solo en forma negativa, sería frágil. Si es fuerte es que produce efectos positivos sobre el deseo y el saber. El poder lejos de impedir el saber lo produce (Foucault 2008b: 757)18.

Es así que no puede existir relación de poder sin la constitución correlativa de un campo de saberes producidos por una variedad de actores y de instituciones. Poder y saber al final son muy parecidos en su conformación. No se enraízan en ningún espacio particular, no son propiedad exclusiva de algunos y sobre todo están en permanente mutación. Finalmente, son todo lo contrario de unas

17 «Le pouvoir ce n'est pas une institution et ce n'est pas une structure, ce n'est pas une certaine puissance dont certains seraient dotés : c'est le nom qu'on prête à une situation stratégique complexe dans une société. » (Foucault, 1976: 123)

18 «Si le pouvoir ne s'exerçait que de façon négative, il serait fragile. S'il est fort c'est qu'il produit des effets positifs au niveau du désir et du savoir. Le pouvoir, loin d'empêcher le savoir, le produit. » 
realidades ontológicas. A continuación presentaremos un ejemplo en el Norte de La Paz de estas relaciones dialécticas poderes-saberes.

\section{2. Ejemplo de la relación saber-poder en el Norte La Paz, el caso del pueblo tacana}

La historia reciente del pueblo tacana demuestra cómo el saber ha sido una fuente de legitimación del poder y cómo la producción de este mismo saber resultó del poder más elevado de este pueblo. La central tacana del Norte de La Paz se fundó en 1992, dos años después de la primera «M archa por la dignidad y el territorio» (1990) que dio un fuerte impulso a las demandas territoriales de los pueblos indígenas del O riente boliviano. En los años 1990, el nivel de autoidentificación del pueblo tacana era muy bajo y el mismo idioma iba desapareciendo. Los niños ya no hablaban Tacana entre ellos. El Cipta, con el apoyo de varias ONG dentro de las cuales W ild life Conservation Society, desempeñó un papel importante en la lucha por recuperar y titularizar sus tierras. En 1997 empezó el pedido de titulación de más de 760000 ha y el 3 de julio de 2003 lograron la titulación efectiva de 325327 ha a nombre del Cipta (Cipta, 2003). Este éxito permitió al pueblo tacana fortalecer su capacidad territorial. Lo interesante es que la producción de este nuevo poder acompañó, de manera dialéctica, la producción de nuevos saberes. El dirigente del Cipta en aquella época lo subrayó:

cuando se inició la organización nuestros principiosfueron: la consolidación de nuestro territorio, preservar nuestras tradiciones y costumbres, manteniendo la solidaridad entre todas las comunidades tacanas (Q uenevo Cartagena \& Delgado, 2007: 5).

Es así que el poder territorial se produce con la afirmación de los saberes en torno a la afirmación de una cultura Tacana.

La producción de estos saberes era necesaria para legitimar el poder territorial, en razón de la ley INRA de 1996. Esta precisa que las tierras serán reconocidas como TCO «siempre y cuando sus titulares mantengan formas de organización, cultura e identidad propias y así lo soliciten» (Congreso Nacional de Bolivia, 1996). Por lo tanto, para entender esta producción hay que ir más allá de esta necesidad inicial (y de una cierta manera legal) de legitimación. La formación de un poder territorial hace surgir la conformación de nuevos saberes. En 2012, tuvimos la oportunidad de entrevistarnos con N eide Cartagena. Fue vicepresidenta del Cipta y tenía el cargo de directora provisoria del Instituto de Lengua y Cultura Tacana (inauguración oficial el 9 de agosto de 2014). Cuando le preguntamos cuál lucha era la más importante, si la lucha por el territorio o la lucha por la cultura, ella respondió:

Como organización, el Cipta, en su primera instancia tuvo que luchar por su territorio, por lo menos se ha consolidado lo que es la TCO, que no es suficiente y que siguen aún luchando por consolidar lo que le falta, luego en su segunda fase viene lo que es la recuperación de su idioma.

Y ella añadió 
Sí, los conocimientos siempre han habido, siempre hemos sabido que somos tacanas, pero lo más valioso, el idioma, no nos lo ha transmitido (Neide Cartagena, directora del Instituto de Lengua y Cultura Tacana, Tumupasa, 30 de abril, 2013).

Ella plantea la relación dinámica entre el fortalecimiento de un poder, otorgado por el reconocimiento de un territorio, y la producción de saberes, en este caso enfocado en la recuperación, que es más bien una reconstrucción de una identidad tacana. De hecho realmente estamos enfrentando un proceso de producción de saberes más que de reapropiación o recuperación de saberes tradicionales. Porque el cambio del medio de difusión, de lo oral a lo escrito, así como de las finalidades de estos saberes y de sus espacios de legitimación (de lo local a lo global/nacional) conducen a un verdadero proceso de producción de nuevos saberes. La influencia de paradigmas globales, en el espíritu del convenio 169 de la O IT sobre pueblos indígenas que se traduce en Bolivia por la adopción de una gobernanza neoliberal sobre la tierra, es cierta. También es obvio el apoyo de actores externos en el proceso de escritura de estos nuevos saberes que va mucho más allá de la tradición de saberes tradicionales para integrar estos nuevos elementos. Es así que esta producción de saberes nuevos se enmarca en relaciones de poder. Por ejemplo, la constitución del Instituto de Lengua y Cultura dependió del reconocimiento oficial del Ministerio de Educación, que es responsable del Instituto Plurinacional de Estudios de Lenguas y Culturas. Los manuales escolares en lengua tacana fueron editados gracias al apoyo de la Unicef, y la misma directora del instituto de lengua tacana fortaleció su poder gracias a su participación en varios talleres de capacitación19. Es así que las redes de poder global (las ONG, Unicef) y nacional (las instituciones estatales) se unen para producir saberes conformes al nuevo poder territorial.

De ahí nace nuestra hipótesiscentral que la relación poder-saber escompletamente dialéctica: cuando cambia el poder territorial tiene que cambiar los saberes que lo sustentan. En el caso tacana hemos pasado de un poder territorial con un espacio de legitimación local y fuentesoralesa un poder territorial garantizado por el Estado nacional con fuentes de legitimación nacional y global (en sus inspiraciones).

\section{CONCLUSIÓN}

El Norte de La Paz está atravesando una época de transformación rápida. La podemos relacionar con los dos últimos procesos de integración: el primero (1990-2005), apoyado por las ONG bajo el concepto de la conservación y del empoderamiento de los indígenas; el segundo (2005 hasta ahora) influenciado

19 «He estado en talleres durante mi cargo de vicepresidenta del Cipta, y me ido formando, he trabajado con WCS, GTZ, Ayuda O brera Suiza AOS, DED, CARE Bolivia, Embajada Holandesa, Bolfor I, Bolfor II, las más fuertes han sido con las 5 primeras» (N eide Cartagena, 3 de abril de 2013, Tumupasa). 
Bolivia: el nexo saber-poder en las reconfiguraciones de un margen en proceso de integración

Cuadro 2 - Dialéctica de producción saber-poder en el caso tacana

\begin{tabular}{|l|c|c|c|c|c|}
\hline & \multicolumn{2}{|c|}{ PODER TERRITO RIAL } & \multicolumn{3}{c|}{ SABER } \\
\cline { 2 - 6 } & $\begin{array}{c}\text { Instrumento } \\
\text { de poder }\end{array}$ & $\begin{array}{c}\text { Espacio de } \\
\text { legitimación }\end{array}$ & $\begin{array}{c}\text { Medio de } \\
\text { expresión }\end{array}$ & $\begin{array}{c}\text { Fuente de } \\
\text { inspiración }\end{array}$ & $\begin{array}{c}\text { Influencia } \\
\text { externa }\end{array}$ \\
\hline $\begin{array}{l}\text { Antes de la } \\
\text { go bernanza } \\
\text { neoliberal } \\
\left(1990^{\prime}\right)\end{array}$ & $\begin{array}{c}\text { Ocupación } \\
\text { de hecho }\end{array}$ & Local & O ral & $\begin{array}{c}\text { Entorno } \\
\text { inmediato } \\
\text { (naturaleza) }\end{array}$ & $\begin{array}{c}\text { Misiones } \\
\text { religiosas / } \\
\text { religión católica }\end{array}$ \\
\hline $\begin{array}{l}\text { A partir de la } \\
\text { gobernanza } \\
\text { neoliberal } \\
\text { (creación } \\
\text { TCO })\end{array}$ & $\begin{array}{c}\text { Título de } \\
\text { propiedad }\end{array}$ & Nacional & Escrito & $\begin{array}{c}\text { Identidad } \\
\text { como } \\
\text { fundamento } \\
\text { del territorio }\end{array}$ & $\begin{array}{c}\text { O NG } \\
\text { conservacionista } \\
\text { / indigenismo } \\
\text { gobernanza } \\
\text { neoliberal }\end{array}$ \\
\hline
\end{tabular}

por la representación de la región como una frontera por conquistar para servir al desarrollo del país entero. Estos dos ciclos tuvieron efectos en las reconfiguraciones de los poderes locales. Los focos de poder se multiplicaron y aparecieron en todos los grupos de actores, más allá de la élite tradicional (las familias que asentaban su poder en la posesión de grandes extensiones de tierra). Es así que la autonomía de los actores locales y su capacidad de acción, directamente relacionados con la ausencia histórica del Estado, evolucionaron fuertemente. El margen, que siempre se caracterizó por la autonomía de los actores locales, se ha convertido ahora en un lugar de innovación social. Nuevos grupos de actores construyen nuevos centros de poder, principalmente en base a su control territorial - mediante la propiedad agraria o el dominio de las redes de comercio-.

Partiendo de estas nuevas relaciones de poder, que se traducen en una conflictividad alta en la región, hemos tratado de exponer los mecanismos internos que llevaban a la producción de estos nuevos poderes y las redes relacionales en las cuales se inscriben a partir de un estudio de caso paradigmático, el del pueblo tacana. El saber se presentó como un incentivo fuerte del poder, permitiendo fortalecer la capacidad territorial de los actores. Pero el nexo poder-saber es todavía más complicado, porque el poder también produce saber. La relación dialéctica entre poder y saber es clave para entender las reconfiguraciones de las relaciones sociales.

Dos temas quedan pendientes. Primero, la relación entre acceso a la información y saber no es tan evidente. Habría que analizar los mismos procesos internos de recepción, transferencia y adaptación de la información hasta la conformación de nuevos saberes. El proceso de apropiación y de construcción de los saberes tendría que ser más problematizado. Segundo, la geografía de las redes de poder debe ser estudiada de manera detallada: los saltos de escalas, los espacios de legitimación del poder, las relaciones entre lo global y lo local, etc. Todos estos procesos especializados de producción de poder influyen en la producción de saber y sería 
importante, en una segunda etapa, tomar en cuenta más precisamente los lugares de coproducción saber-poder.

\section{Referencias citadas}

ANDREUCCI, D. \& RADHUBER, I. M., 2015 - Limits to 'counter-Neoliberal' Reform: M ining Expansion and the M arginalisation of Post-Extractivist Forces in Evo M orales's Bolivia. Geoforum, O ctober 12. doi:10.1016/j.geoforum.2015.09.002.

AMIN, S., 1973 - Le développement inégal. essai sur les formations sociales du capitalisme périphérique, 365 pp.; París: Editions de Minuit.

ARZE CUADROS, E., 2002 - Bolivia, el programa del MNR y la revolución nacional: del movimiento de reforma universitaria al ocaso del modelo neoliberal (1928-2002), 724 pp.; La Paz: Plural Editores.

BEBBINGTON, A., 2012 - Social Conflict, Economic Development and the Extractive Industry: Evidence from South America, xxii + 256 pp.; Londres, Nueva York: Routledge.

BRID GE, G., 2014 - Resource Geographies II The Resource-State N exus. Progress in Human Geography, 38 (1): 118-30. doi:10.1177/0309132513493379.

BRID GE, G. \& JO NAS, A., 2002 - Governing Nature: The Reregulation of Resource Access, Production, and Consumption. Environment and Planning A, 34 (5): 759-66. doi:10.1068/a34199.

BRIDGE, G. \& PERREAU LT, T., 2009 - Environmental Governance. In: A Companion to Environmental Geography (N. Castree, ed.): 475-497; Chichester, U.K: WileyBlackwell.

CALDERÓ N, R., 2014 - Territorio geográfico, cultural e históricamente definido, pero de compleja afirmación jurídico administrativa. Proceso y casos de la transición de norte caupolicano a Iturralde (siglo XIX y primeras décadas del XX). In: El Norte La Paz en la encrucijada de la integración (L. Perrier Bruslé \& B. Gozalvez, eds.): 83114; La Paz: Plural Editores, IRD Editions, UMSA.

CALLA, R., 2011 - TIPNIS y Amazonia: contradicciones en la agenda ecológica de Bolivia. European Review of Latin American and Caribbean Studies, $\mathbf{n} .{ }^{\circ}$ 92: 77-83.

CAM BIO , 2014 - García Linera exhorta a unir esfuerzos para que La Paz retome su liderazgo, July 17; La Paz: Imprenta edition. http://www.cambio.bo/?q=garc\%C3\%ADalinera-exhorta-unir-esfuerzos-para-que-la-paz-retome-su-liderazgo.

CEJUDO CORDOBA, R., 2007 - Capacidades y libertad. Una aproximación a la teoría de Amartya Sen. Revista Internacional de Sociología, LXV (47): 9-22.

CIPTA, Consejo Indígena del Pueblo Tacana. 2003 - Estrategia de desarrollo sostenible TCO Tacana, 25 pp.; Bolivia: CIPTA, WCS, AOS.

CIPTA, Consejo Indígena del Pueblo Tacana, DELGADO , K. L. \& LEH M ARDAYA, S., 2008 Reglamento de acceso, uso y aprovechamiento de los recursos naturales renovables del territorio indígena Takana; La Paz: CIPTA-Consejo Indígena del Pueblo Tacana.

CONGRESO NACIO NAL DE BO LIVIA, 1996 - Ley del servicio nacional de reforma agraria. CO RI, J., 2014 - MAS ofrece proyectos carreteros y productivos al norte de La Paz. Cambio, August 16; La Paz: Imprenta edition. http://www.cambio.bo/?q=mas-ofreceproyectos-carreteros-y-productivos-al-norte-de-la-paz. 
Bolivia: el nexo saber-poder en las reconfiguraciones de un margen en proceso de integración

CORZ, C., 2014 - El INRA distribuye dos millones de ha de tierras fiscales. La Razón, September 22. http://www.la-razon.com/index.php?_url=/economia/INRAdistribuye-millones-tierras-fiscales_0_2130387014.html.

ERBO L, 2013a - Amenazan con justicia indígena a líder campesino. ERBO L Digital, November 13. http://www.erbol.com.bo/noticia/indigenas/13112013/amenazan_ con_justicia_indigena_lider_campesino.

ERBO L, 2013b - Denuncian que colonos tienen 100 comunidades 'fantasmas. ERBO L Digital, November 14. http://erbol.com.bo/noticia/indigenas/14112013/ denuncian_que_colonos_tienen_100_comunidades_fantasmas.

ESTADO PLURINACIO NAL DE BO LIVIA, 2009 - Constitución política del Estado.

FIFER, V., 1976 - Bolivia. territorio, situación y política, desde 1825, 474 pp.; Buenos Aires: Editorial Francisco de Aguirre.

FO U CAU LT, M ., 1976 - La volonté de savoir, 224 pp.; París: Gallimard.

FOU CAU LT, M., 2008a - Dits et écrits, tome II, 1735 pp.; París: Gallimard.

FO U CAU LT, M., 2008b - Pouvoir et Corps (texte $\left.n^{\circ} 157\right)$. Entretien de 1975. In: Dits et Ecrits, Tome II; París: Gallimard.

FO NTAN A, L. B. \& GRU GEL, J., 2016 - The Politics of Indigenous Participation Through 'Free Prior Informed Consent': Reflections from the Bolivian Case. World Development, 77 (January 2016): 249-61. doi:10.1016/j.worlddev.2015.08.023.

FUNDACIÓN TIERRA, 2011 - Vida al límite - indígenas y campesinos en la Amazonia; Fundación TIERRA, December 4.

http://www.ftierra.org/tierra2012/index.php?option=com_content\&view=article\& id = 5623: rair\& catid $=98$ : noticias\& $/$ temid $=243$.

GARCÍA JO RDÁN, P., 2001 - Cruz y arado, fusiles y discursos, la construcción de los orientes en el Perú y Bolivia 1820-1940, 476 pp.; Lima: IFEA, IEP.

GRO FF GREEVER, J., 1987 - José Ballivián y el O riente boliviano, xvi + 224 pp.; La Paz: Siglo.

GRUGEL, J. \& RIGGIROZZI, P., 2012 - Post-N eoliberalism in Latin America: Rebuilding and Reclaiming the State after Crisis. Development and Change, 43 (1): 1-21. doi:10.1111/j.1467-7660.2011.01746.x.

GUDYNAS, E., 2012 - Estado compensador y nuevos extractivismos. Las ambivalencias del progresismo sudamericano. Nueva Sociedad, $\mathbf{n} .^{\circ}$ 237: $128-46$.

HAARSTAD, H. \& ANDERSON, V., 2009 - Backlash Reconsidered: Neoliberalism and Popular Mobilization in Bolivia. Latin American Politics and Society, 51 (4): 1-28.

HERRERA SARMIENTO, E., 2009 - Derechos territoriales indígenas en la Amazonía boliviana y creación de lo «tacana». In: El regreso de lo indígena: retos, problemas y perspectivas (V. Robin Azevedo \& C. Salazar-Soler, eds.): 159-185; Lima: Institut français d'études andines.

JO NES, K. T., 1998 - Scale as Epistemology. Political Geography, 17 (1): 25-28. doi:10.1016/ S0962-6298(97)00049-8.

KAUP, B. Z., 2010 - A Neoliberal Nationalization?: The Constraints on Natural-GasLed Development in Bolivia. Latin American Perspectives, 37 (3): 123-38. doi:10.1177/0094582X10366534.

KO H L, B., 2002 - Stabilizing N eoliberalism in Bolivia: Popular Participation and Privatization. Political Geography, 21 (4): 449-72. doi:10.1016/S0962-6298(01)00078-6.

KRINGS, L., 2014 - Entre conservación y desarrollo: cacaoteros asumen su rol en un proceso de multi-escala e integración. In: El Norte La Paz en la encrucijada de la integración juegos de actores y de escala en un margen boliviano (L. Perrier Bruslé \& B. Gosalvez, eds.): 169-85; La Paz: U MSA, IRD Éditions, Plural Editores. 
LAATS, H., 2011 - Megaobras en Madidi y Pilón Lajas. Hacia una transformación de los conflictos, xviii + 164 pp.; La Paz: PIEB.

LAVAU D, J.-P., 2007 - Bolivie : Un Avenir Politique Hypothéqué ? Nueva Sociedad, 209: $17 \mathrm{pp}$.

MENACHO, N., 2014 - Tres zonas tienen el 87\% de tierras fiscales. El Deber, October 11 , sec. Rural. http://www.eldeber.com.bo/economia/tres-zonas-87-tierras-fiscales. html.

MENDIETA, P., 2014 - De la quina a la goma: la compleja incorporación de la provincia Caupolicán al mercado mundial (siglo XIX). In: El Norte La Paz en la encrucijada de la integración (L. Perrier Bruslé \& B. Gozalvez, eds.): 57-81; La Paz: Plural Editores, IRD Éditions, UMSA.

NEU M ANN, R., 2009 - Political Ecology: Theorizing Scale. Progress in Human Geography, 33 (3): 398-406.

NUSSBAU M, M., 2003 - Capabilities as Fundamental Entitlements: Sen and Social Justice. Feminist Economics, 9 (2-3): 33-59. doi:10.1080/1354570022000077926.

OLIVIER, L., 1988 - La question du pouvoir chez Foucault : espace, stratégie et dispositif. Canadian Journal of Political Science/Revue Canadienne de Science Politique, $\mathbf{2 1}$ (01): 83-98. doi : 10.1017/S0008423900055621.

PAINTER, M., CASTILLO , O ., N OSS, A., PAINTER, L. \& WALLACE, R., 2008 - Consolidating Protected Areas as Part of a Strategy for Landscape and Species Conservation: Lessons from Bolivia. In: Protected Areas, Governance, and Scale (K. Redford \& K. Grippo, eds.): 73-82; Nueva York: Working Papers 36.

PECK, J. \& TICKELL, A., 2002 - Neoliberalizing Space. Antipode, 34 (3): 380-404. doi:10.1111/1467-8330.00247.

PERREAULT, T. \& MARTIN, P., 2005 - Geographies of Neoliberalism in Latin America. Environment and Planning A, 37 (2): 191-201. Doi:10.1068/a37394.

PERRIER BRUSLÉ, L., 2005 - La dernière frontière, loin des Andes, trop près du Brésil. La frontière orientale et la construction du territoire en Bolivie. París: Université Paris 1-Panthéon Sorbonne. Thèse de doctorat de géographie.

PERRIER BRUSLÉ, L., 2007 - The Front and the Line: The Paradox of South American Frontiers Applied to the Bolivian Case. Geopolitics, 12 (1): 57-77.

PERRIER BRU SLÉ, L., 2012 - Le conflit du Tipnis et la Bolivie d'Evo Morales face à ses contradictions: analyse d'un conflit socio-environnemental. EchoGéo, Sur le Vif 2012, January. http://echogeo. revues.org/12972.

PERRIER BRU SLÉ, L. \& GOSALVEZ, B. (eds.), 2014 - El Norte La Paz en la encrucijada de la integración. juegos de actores y de escala en un margen boliviano, 268 pp.; La Paz: Plural Editores, IRD Éditions, UMSA.

POSTERO, N. G., 2007 - Now We Are Citizens: Indigenous Politics in Postmulticultural Bolivia, xvi + 294 pp.; Stanford: Stanford U niversity Press.

QUENEVO CARTAGENA, C. \& DELGADO, K. L., 2007 - Pueblo indígena tacana, consolidación y gestión territorial; Tumupasa: Cipta-Consejo Indígena del Pueblo Tacana.

RAFFESTIN, C., 1980 - Pour une géographie du pouvoir, x + 249 pp.; París: Librairies techniques.

REYNAUD, A., 1981 - Société, espace et justice. Inégalités régionales et justice sociospaciale, 263 pp.; París: PUF.

RO BEYNS, I., 2011 - The Capability Approach. In: The Stanford Encyclopedia of Philosophy (E. N. Zalta, ed.); Stanford: Stanford U niversity Press. URL http://plato.stanford.edu/ entries/capability-approach/ 
Bolivia: el nexo saber-poder en las reconfiguraciones de un margen en proceso de integración

RO CA, J. L., 2001 - Economia y sociedad en el oriente boliviano (Siglos XVI-XX ), 678 pp.; Santa Cruz: Cotas.

ROUX, J.-C., 1997 - Bolivia mítica y Bolivia real a través del primer mapa nacional de 1859. In: El espacio territorial y los orientes bolivianos (J.-C. Roux \& Cordova, eds.): 77-119; La Paz: UMSA.

SCOTT, J. C., 1998 - Seeing like a State: How Certain Schemes to Improve the Human Condition Have Failed, xiv + 445 pp.; New Haven: Yale U niversity Press.

SCOTT, J. C., 2009 - The Art of Not Being Governed. An Anarchist History of Upland Southeast Asia. xviii + 442 pp.; New Haven, Londres: Yale U niversity Press.

SEN, A., 1981 - Poverty and Famines: An Essay on Entitlement and Deprivation, ix + 257 pp.; O xford, Nueva York: Clarendon Press, O xford U niversity Press.

SEN, A., 1985 - Well-Being, Agency and Freedom: The Dewey Lectures 1984. The Journal of Philosophy, 82 (4): 169-221. Doi:10.2307/2026184.

SEN , A., 1992 - Inequality Reexamined, xiv + 207 pp.; Nueva York: Russell Sage Foundation.

SEN, A., 1999a - Commodities and Capabilities. ix + 89 pp.; Delhi, Nueva York: Oxford University Press.

SEN , A., 1999b - Development as Freedom. xvi + 366 pp.; Nueva York: Knopf.

SEN, A., 2005 - Human Rights and Capabilities. Journal of Human Development, 6 (2): 151-66. Doi:10.1080/14649880500120491.

STEFANO NI, P. \& SAINT U PÉRY, M., 2011 - La Bolivie d'Evo Morales entre progrès et désenchantement. Mediapart, 10 de marzo.

STRÖ HER, H., 2013 - La distribución de tierras y la representatividad de organizaciones indígenas: un caso de estudio en la Amazonía de Bolivia. In: ¿Quién habla por quién? representatividad y legitimidad de organizaciones y representantes indígenas. un debate abierto (S. Speiser, ed.):174-200; Quito: Deutsche Gesellschaft für Internationale Zusammenarbeit (GIZ) GmbH .

STRÖHER, H., 2014 - ¿A quién pertenecen las tierras? Un análisis de los intereses territoriales para la antigua concesión proinsa en el Norte de La Paz. In: El Norte La Paz en la encrucijada de la integración juegos de actores y de escala en un margen boliviano (L. Perrier Bruslé \& B. Gosalvez, eds.): 235-254; La Paz: Plural Editores, IRD Éditions, UMSA.

TAPIA MEALLA, L., 2014 - La sustitución del pueblo, 139 pp.; La Paz: Editorial Autodeterminación. Colección El horizonte interior.

TURNER, J., 1893 - The Significance of the Frontier in American History. Report of the American Historical Association, 1893: 199-227.

TOCKMAN, J. \& CAM ERON, J., 2014 - Indigenous Autonomy and the Contradictions of Plurinationalism in Bolivia. Latin American Politics and Society, 56, $\mathbf{n} .^{\circ} \mathbf{3}$ (September 1): 46-69. doi:10.1111/j.1548-2456.2014.00239.x.

VALE, M., 2015 - Gobierno construirá las tres vías fundamentales de integración del siglo XXI en Bolivia. Cambio. O ctober 19. Digital edition, sec. Economia. http://www. cambio.bo/gobierno-construir\%C3\%A1-las-tres-v\%C3\%ADas-fundamentales-deintegraci\%C3\%B3n-del-siglo-xxi-en-bolivia. 